Indian Journal of Information Sources and Services

ISSN: 2231-6094 Vol. 9 No.1, 2019, pp. 14-21

(C) The Research Publication, www.trp.org.in

\title{
Economics Research Output in BRICS Countries: A Scientometric Dimension
}

\author{
Kiran P. Savanur \\ Assistant Professor, Department of Library and Information Science, \\ Rani Channamma University, Belagavi, Karnataka India \\ E-Mail: kps@rcub.ac.in
}

\begin{abstract}
This article examines the research output of economics published by BRICS countries during 1991-2016. Data collected from the Web of Science database. Growth rate (CAGR), Collaboration index, Transformative Activity index (TAI), Co-authorship index and Relative Citation Impact (RCI) indicators have been adopted to analyze the quantity and impact of economic research. We found that all five BRICS countries contributed approximately 10 percentile of the world's economics research. The highest contribution was made by China with a total of 4424 articles which is $\mathbf{4 0 . 5 9}$ percent. Russia has the maximum growth rate of 27.99. Overall collaboration rate of economics publications of BRICS countries is moderate.
\end{abstract}

Keywords: Economics, Research Output, BRICS Countries, Scientometric Dimension

\section{INTRODUCTION}

BRICS is an international association of five emerging countries. They are the major emerging economies in the world. Among the emerging countries - Brazil, Russia, India, China and South Africa are in this group. BRIC association formed since at the end of the 2000s and since 2009 their leaders meet regularly in formal summits, held in one of the countries. In 2010, South Africa joined the Association. According to IMF (2013) and Christian Science Monitor (2011) "the five BRICS countries represent about $41 \%$ of the world population; As of 2018, these five nations have a combined nominal GDP of US\$18.6 trillion, about $23.2 \%$ of the gross world product, combined GDP (PPP) of around US\$40.55 trillion (32\% of World's GDP PPP) and an estimated US $\$ 4.46$ trillion in combined foreign reserves" (Wikipedia, accessed Dec 2018). In recent years, much attention has been paid on the study and highlights the potentials of the BRICS countries. Among these studies, there are ample of scientometric studies on growth of publication activity (Kumar and Asheulova, 2011), (Savanur and Bakanatti, 2018) (Shashnov and Kotsemir, 2018) thematic structure of publications (Yang et al., , 2012), citation and visibility (Yi et al., 2013), scientific collaboration (Bouabid, Paul-Hus and Lariviere, 2016) were conducted on the BRICS countries and in comparison with economically developed nations and associations like G7. In these studies, much importance was given for science, technology, medicine subjects. In the present study, an attempt has been made to analyze the research output of economics subject of BRICS countries published during 1991-2016.

\section{REVIEW OF LITERATURE}

Kumar and Asheulova (2011). This article presented a comparative analysis of the growth of publication share of BRIC countries with that of US in terms of world output on the emerging areas of science. The data extracted from the Scopus database during 1980-2009. The analysis showed that "... publication output is skewed towards China after 1994, while Russia's progression seems relatively slow... It is significant to mention that China produced $\sim 13$ percent papers of the total world publications, second to the United States, which has $\sim 24$ percent share of the global publication share. China was followed by India (2.8\%), Russia (1.6\%) and Brazil (2.0\%) and the total BRIC publication share was nearly 19 percent of the global publication in 2009" (p.231).

Chitra, Jeyshankar, and Abu (2014). In this paper, the authors analysed the research output of lung cancer published by G7 (US, UK, France, Germany, Italy, Canada and Japan) and BRIC countries. The data extracted from the Scopus database for athe period of ten years (2003-2012). The scientometric indicators like Comparative the Growth Rate (CAGR), Collaboration Coefficient (CC) and Transformative Activity Index (TAI), Absolute Citation Impact (ACI), Relative Citation Impact (RCI), and Coauthorship index have been adopted to compare the quality and impact of the lung cancer research. The results showed that "Among the G7 countries, US topped with 27375 (44.58\%) papers, followed by Japan with 10666 (17.37\%). Among the BRIC countries, China topped with 9759 (78.82\%) papers, followed by India with 1519 (12.27\%) papers. China had the highest growth rate of 26.16 followed by India (23.20), Brazil (11.11) and finally Russia (4.93). When the G7 countries were compared with the BRIC countries highest collaboration (CC) rate of 0.80 followed by China (0.79) and Italy (0.78)...the publication activity has increased considerably for the BRIC countries such as China, India and Brazil. For US, UK, France and Canada, $\mathrm{RCI}$ is more than 1 , indicating higher citation impact that the world rate. Italy, Germany and Russia with $\mathrm{RCI}=0.96$ to 0.99 have almost equal to world citation rate. Brazil, India, China and Japan have RCI value less than 1 indicates that the research efforts are higher than visibility and impact" (p.75-80). 
Elango, Rajendran and Manickraj (2013). In this paper authors attempted to analyze the Tribology research output among the BRIC countries published during 2006-2010, Scopus database was consulted for the extraction of data for the study. The results of this study showed that "Among the BRIC countries, China topped with 3536 (80.27\%) papers, followed by India 537 (12.19\%), Russia 202 (4.59\%) and finally Brazil $130(2.95 \%)$. Russia recorded the higher growth rate of $63.81 \% \ldots$ Brazil and China have been recorded higher collaboration rate of 0.689 followed by India with 0.616 and Russia with $0.591 \ldots$ A higherincrease of TAI was observed for Russia with 43 and decrease for Brazil with $34 .$. . Out of total papers, 2276 papers received 11303 citations during 2005 - 2012 (up to 15.04.2012) with an average rate of citation as $\sim 5$ " (p.4-6).

Balasubramani, Siriwardena and Abu (2015). In this paper, the authors attempted to analyze the publications published by BRIC countries supported by funding agencies, data for the study captured from the Web of Science database. The findings of the study revealed that "China had published the maximum number funding supported SCI papers, contributing to 652,709 records. In the top three funding agencies, CNPQ contributes the maximum number of publications in Brazil, RFBR in Russia, CSIR in India. In the extent of International collaboration, Brazil, India and China had a maximum number of collaborations with the USA. Russia has the maximum number of collaborations with Germany. The majority of research papers came from areas Chemistry, Physics in Brazil, India and China." (p.260).

The paper by Biradar \& Tadasad (2015), analyzed the pattern of authorship and collaboration by considering various indicators such as Collaborative index, Degree of collaboration, Collaboration co-efficient in Economics subject. The data for the study collected form Social Science Citation Index, WoS during 2000-2014. It was found that the majority of papers are single-authored (41.67\%), the authors claim that there was a gradual shift from solo research to the collaboration research. The collaborative index varies from 1.8 in 2003 with the highest in 2014 of 2.29. There was an increase in collaboration coefficient from 0.31 to 0.14 from the year 2000-2014. The highest degree of collaboration (0.58) was during 20002014.

\section{OBJECTIVES OF THE STUDY}

1. To analyze the growth of publication share in BRICS countries in economics subject during 1991-2016;

2. To analyze the collaboration pattern and activity profile of economics research output; and

3. To analyze the citation profile and Relative Citation Index of economics research output.

\section{METHODOLOGY}

The present study focused on economics research output published by BRICS countries during 1991-2016. The data for this study collected from the Web of Knowledge portal, a comprehensive citation indexing database containing databases on sciences, social sciences and arts and humanities. The query was designed by referring to the various topics in the subject and the country. The bibliographic fields like author, source title, year, citations, type of documents, etc. were exported to and analyzed using MS Excel software. Further, the datasets were analyzed using the scientometric indicators like Compound Annual Growth Rate, collaboration index, co-authorship index, transformative activity index, relative citation impact to draw the conclusions.

\section{ANALYSIS AND DISCUSSION}

The research output and growth rate of the BRICS countries in economics subject from 1991-2016 is shown in Table I.

All the five BRICS countries produced roughly 10924 publications in economics subject field during 1991-2016, accounting for approximately 10 percent of world's papers published in journals indexed by the Web of Science database. The highest contribution was made by China with a total of 4424 articles which is 40.59 percent. China is experiencing faster growth of publications not only among BRICS country but in the world of science and technology. Kumar \& Asheulova (2011) argued that "China has a sharp rise that dwarfs other BRIC nations and may catch up with the United States in the near future... China produced $\sim 13$ percent papers of the total world publications in all fields of science, second to the United States, which has 24 percent share of the global publication share" (p.231). A great deal of $(70 \%)$ articles of China was published between 20112016. Followed by Brazil with 1987 (18.2\%) articles. India had published $1924(17.6 \%)$ articles. There was a steady growth of Indian publications during the period of study. Russia has the lowest number with 1162 articles making 10.64 percent of the total. It's interesting to note that 65 percent of the total publications were published in 2015 and 2016. The year of maximum output for India, Brazil, Russia, China and South Africa is 2015 and 2016.

The growth rate is measured using the formula of CAGR or Compound Annual growth rate1. It gives the average rate of increase per year. The value is appropriate for comparing the growth rates between different countries.

$$
\mathrm{CAGR}=\left(\frac{\text { Ending Value }}{\text { Begining Value }}\right)^{\frac{1}{n-1}}-1
$$

Where $n$ is the number of years. In our case $n=26$. Russia has the maximum growth rate of 27.99 , though Russia had the lowest number of articles as compared to other BRICS countries, the publications shot up in the years 2015 and 2016 with the phenomenal growth of $37 \%$ of the total articles. Brazil with 26.69 and China with 24.04 percentile. China could have been the highest growth rate but in this study, it has no publications during 1991 and 1992. India has the lowest growth rate at 12.86 . The table below shows the total output of BRICS countries as a single unit in comparison with the world output. 
TABLE I YeAR-Wise Growth OF ECONOMICS PUblicATIONS OF BRICS COUNTRIES

\begin{tabular}{|c|c|c|c|c|c|c|c|}
\hline \multirow{2}{*}{ Year } & \multicolumn{5}{|c|}{ Country } & \multirow{2}{*}{ BRICS Output } & \multirow{2}{*}{ World output } \\
\hline & Brazil & China & India & Russia & South Africa & & \\
\hline 1991 & 1 & - & 14 & - & 11 & 26 & 1024 \\
\hline 1992 & 10 & - & 21 & 1 & 2 & 34 & 1477 \\
\hline 1993 & 7 & 4 & 27 & 9 & 11 & 58 & 1625 \\
\hline 1994 & 7 & 7 & 17 & 5 & 8 & 44 & 1704 \\
\hline 1995 & 11 & 11 & 31 & 10 & 14 & 77 & 1939 \\
\hline 1996 & 11 & 9 & 34 & 7 & 7 & 68 & 1964 \\
\hline 1997 & 13 & 11 & 22 & 10 & 13 & 69 & 2029 \\
\hline 1998 & 17 & 17 & 27 & 10 & 11 & 82 & 2241 \\
\hline 1999 & 20 & 23 & 27 & 13 & 9 & 92 & 2363 \\
\hline 2000 & 23 & 39 & 44 & 9 & 24 & 139 & 2656 \\
\hline 2001 & 23 & 50 & 45 & 14 & 16 & 148 & 2613 \\
\hline 2002 & 23 & 65 & 43 & 13 & 19 & 163 & 2801 \\
\hline 2003 & 28 & 58 & 37 & 10 & 24 & 157 & 2894 \\
\hline 2004 & 22 & 79 & 39 & 22 & 27 & 189 & 2928 \\
\hline 2005 & 30 & 73 & 43 & 13 & 43 & 202 & 3262 \\
\hline 2006 & 50 & 94 & 47 & 12 & 36 & 239 & 3671 \\
\hline 2007 & 64 & 112 & 79 & 15 & 45 & 315 & 4312 \\
\hline 2008 & 104 & 145 & 78 & 19 & 62 & 408 & 4931 \\
\hline 2009 & 117 & 208 & 97 & 15 & 75 & 512 & 5802 \\
\hline 2010 & 112 & 247 & 68 & 26 & 81 & 534 & 6039 \\
\hline 2011 & 136 & 302 & 99 & 24 & 111 & 672 & 6251 \\
\hline 2012 & 154 & 346 & 127 & 27 & 108 & 762 & 6770 \\
\hline 2013 & 144 & 413 & 147 & 26 & 114 & 844 & 7308 \\
\hline 2014 & 132 & 520 & 154 & 44 & 132 & 982 & 7625 \\
\hline 2015 & 358 & 720 & 268 & 330 & 187 & 1863 & 11057 \\
\hline 2016 & 370 & 874 & 289 & 478 & 234 & 2245 & 11938 \\
\hline Total Publications & 1987 & 4427 & 1924 & 1162 & 1424 & 10924 & 109224 \\
\hline$\%$ of publications & 18.19 & 40.53 & 17.61 & 10.64 & 13.04 & & \\
\hline CAGR & 26.69 & 24.04 & 12.87 & 27.99 & 13.01 & & \\
\hline \multicolumn{7}{|c|}{ CAGR: Compound Annual Growth Rate } & \\
\hline
\end{tabular}

The total BRICS share has been consecutively increasing in the total output as the numbers indicate in the above table. The increment has occurred from 2.54 percentile in 1991 to 18.81 percentile in the year 2016. Therefore BRICS as a developing economy even shares a considerable amount of research output being 10 percentile in the Economics field.

Shashnov and Kotsemir (2018) in their study on research landscape of BRICS countries found that "In 2010, the total number of publications of BRICS countries exceeded the number of publications in the United States, and in 2014, BRICS countries almost closed the gap with EU-28 countries. In total, in 2015, the BRICS countries accounted for almost $29 \%$ of the global volume of publications. Largely this was achieved through the exceptionally high rate of growth of publication activity in China" (p.1126).

Even the Citation ratio has increased from 0.42 percentile in 1991 to 35.85 percentile in 2016 and a slight decrease to 4.02 percentile and 4.8 percentile in the year 2002 and 2003 respectively. Citations received to the BRICS publications contributed to 8 percentile of the total citations of the world publications. 
TABLE II COMPARISON BETWEEN BRICS OUTPUT TO THAT OF THE WORLD

\begin{tabular}{|c|c|c|c|c|c|c|c|}
\hline Year & $\begin{array}{l}\text { BRICS } \\
\text { output }\end{array}$ & $\begin{array}{r}\text { World } \\
\text { output }\end{array}$ & $\begin{array}{c}\text { Percentage } \\
\text { share of BRICS }\end{array}$ & Year & $\begin{array}{c}\text { Citation received } \\
\text { by BRICS }\end{array}$ & $\begin{array}{c}\text { Citations of } \\
\text { the world }\end{array}$ & $\begin{array}{c}\text { Percentage share } \\
\text { of BRICS }\end{array}$ \\
\hline 1991 & 26 & 1024 & 2.54 & 1991 & 70 & 16533 & 0.42 \\
\hline 1992 & 34 & 1477 & 2.30 & 1992 & 182 & 30524 & 0.60 \\
\hline 1993 & 58 & 1625 & 3.57 & 1993 & 448 & 38603 & 1.16 \\
\hline 1994 & 44 & 1704 & 2.58 & 1994 & 463 & 33832 & 1.37 \\
\hline 1995 & 77 & 1939 & 3.97 & 1995 & 768 & 51471 & 1.49 \\
\hline 1996 & 68 & 1964 & 3.46 & 1996 & 1044 & 46363 & 2.25 \\
\hline 1997 & 69 & 2029 & 3.40 & 1997 & 1634 & 58733 & 2.78 \\
\hline 1998 & 82 & 2241 & 3.66 & 1998 & 1297 & 65304 & 1.99 \\
\hline 1999 & 92 & 2363 & 3.89 & 1999 & 2349 & 69075 & 3.40 \\
\hline 2000 & 139 & 2656 & 5.23 & 2000 & 4717 & 90485 & 5.21 \\
\hline 2001 & 148 & 2613 & 5.66 & 2001 & 3492 & 69959 & 4.99 \\
\hline 2002 & 163 & 2801 & 5.82 & 2002 & 3397 & 84477 & 4.02 \\
\hline 2003 & 157 & 2894 & 5.43 & 2003 & 4086 & 85079 & 4.80 \\
\hline 2004 & 189 & 2928 & 6.45 & 2004 & 10133 & 90123 & 11.24 \\
\hline 2005 & 202 & 3262 & 6.19 & 2005 & 5202 & 90428 & 5.75 \\
\hline 2006 & 239 & 3671 & 6.51 & 2006 & 7737 & 98076 & 7.89 \\
\hline 2007 & 315 & 4312 & 7.31 & 2007 & 6524 & 97628 & 6.68 \\
\hline 2008 & 408 & 4931 & 8.27 & 2008 & 11652 & 100610 & 11.58 \\
\hline 2009 & 512 & 5802 & 8.82 & 2009 & 10026 & 106070 & 9.45 \\
\hline 2010 & 534 & 6039 & 8.84 & 2010 & 9816 & 93223 & 10.53 \\
\hline 2011 & 672 & 6251 & 10.75 & 2011 & 13614 & 85089 & 16.00 \\
\hline 2012 & 762 & 6770 & 11.26 & 2012 & 9356 & 74003 & 12.64 \\
\hline 2013 & 844 & 7308 & 11.55 & 2013 & 8833 & 64007 & 13.80 \\
\hline 2014 & 982 & 7625 & 12.88 & 2014 & 8075 & 51470 & 15.69 \\
\hline 2015 & 1863 & 11057 & 16.85 & 2015 & 11198 & 35966 & 31.13 \\
\hline 2016 & 2245 & 11938 & 18.81 & 2016 & 6466 & 18034 & 35.85 \\
\hline Total & 10924 & 109224 & 10.00 & Total & 139567 & 1745165 & 8.00 \\
\hline
\end{tabular}

\section{A. Measure of Collaboration}

The collaboration between authors and that too between different countries brings in more consolidated and stronger results because such results suit different scenarios and conditions as tested and evaluated by the respective scientists of the different countries. In this section, an attempt has been made to study the authorship pattern by counting single and multi-authored papers. This study helps to find out collaboration patterns and related Scientometric indicators.

Scientometric indicators strive to measure the factors and coefficients which govern and quantify the collaborations between the authors. But not all indicators provide an insight into the collaborative patterns. Hence a few selected Scientometric indicators are used in this study, as discussed in (Savanur\&Srikanth. 2010).
Collaborative Coefficient $(C C)$ : Proposed by Ajiferuke et al., (1988). It gives a proper number which expresses the level of collaboration. The shortcomings of Collaborative Index (CI) and Degree of Collaboration (DC) are solved by CC. The Collaborative coefficient lies between 0 and 1 . The result yields 0 for only single-authored papers and a digit nearer to 1 for all maximal multi-authored papers.

$$
\text { Collaborative Coefficient }=1-\frac{\sum_{j=1}^{A} \frac{f_{j}}{j}}{N}
$$

Where $f j$ is the number of papers having $j$ authors in collection $\mathrm{K}$;

$\mathrm{N}$ is the total number of papers in $\mathrm{K}$.

$\mathrm{A}$ is the total number of authors in collection $\mathrm{K}$.

Modified Collaborative Coefficient (MCC): Proposed by Savanur \& Srikanth (2010). It is a modified version of Collaborative coefficient (MCC). The benefit of MCC is that its value tends to one as the number of the sum of 
collaborative authors goes on increasing unlike that of Collaborative coefficient which remains less than one.

Modified Collaborative Coefficient $=\frac{A}{A-1}\left\{1-\frac{\sum_{j=1}^{A} \frac{f_{j}}{j}}{N}\right\}$

Table III provides the authorship and collaboration pattern of BRICS countries and the year-wise collaboration rate is depicted in figure 1. It can be observed that Brazil and
China have maximum collaboration rate of 0.56 , followed by India (0.52), South Africa (0.43) and Russia has the lowest collaboration rate i.e. 0.29 , the great deal of $(54 \%)$ Russian economics papers are single-authored. Overall collaboration rate of economics publications of BRICS countries is moderate. A similar result of the collaborative rate of 0.38 was observed (Biradar \& Tadasad, 2015) for the world economics literature published during 2000-2014.

TABle III Collaboration RATE OF The Brics Countries

\begin{tabular}{|l|c|c|c|c|c|c|c|}
\hline Country & Single Aut & 2- Aut & 3- Aut & >3 Aut & Total & CC & MCC \\
\hline Brazil & 378 & 469 & 364 & 771 & 1982 & 0.56 & 0.56 \\
\hline China & 732 & 1098 & 1097 & 1497 & 4424 & 0.56 & 0.56 \\
\hline India & 420 & 480 & 407 & 615 & 1922 & 0.52 & 0.52 \\
\hline Russia & 632 & 260 & 132 & 140 & 1164 & 0.29 & 0.29 \\
\hline South Africa & 483 & 394 & 218 & 311 & 1406 & 0.43 & 0.43 \\
\hline
\end{tabular}

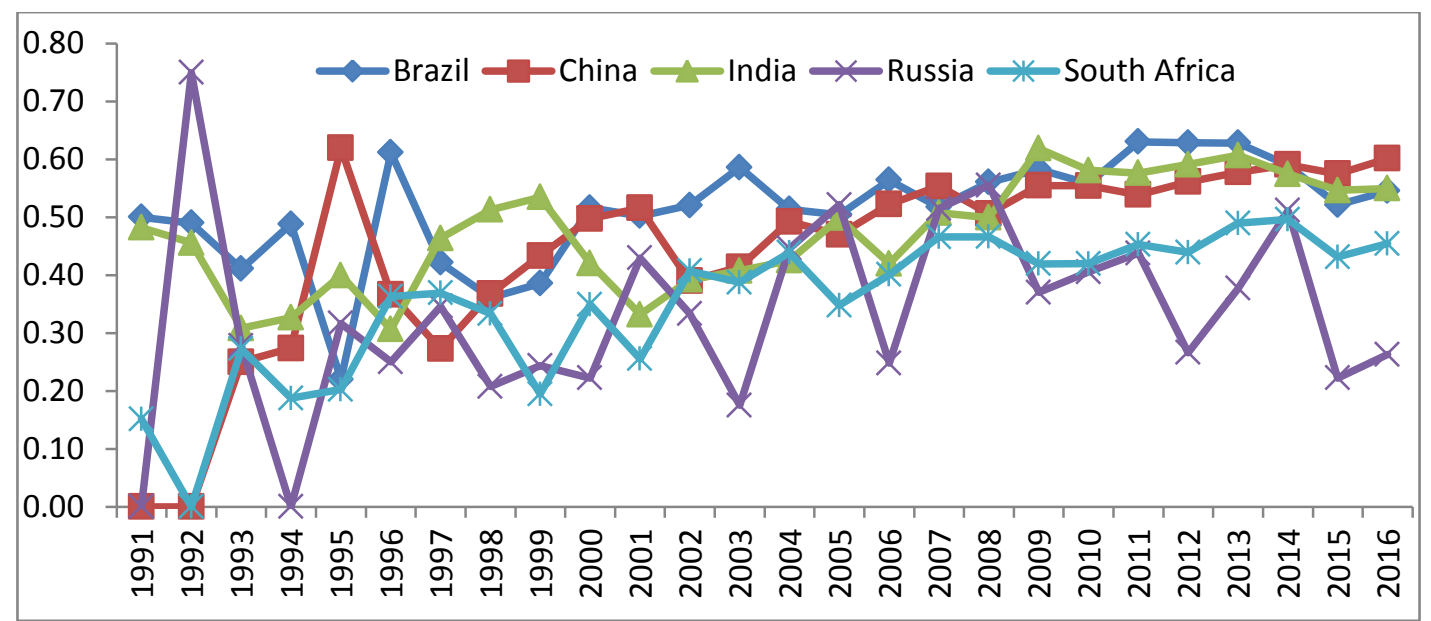

Fig. 1 Collaborative Coefficient (CC) of BRICS Countries

\section{B. Co-Authorship Pattern of the BRICS Countries}

Schubert and Braun (1996) "suggested the use of CoAuthorship Index for the first time, and is obtained by calculating proportionally the publications by single, two, multi- and mega-authored papers for different nations or for different sub-disciplines.

The Co-authorship Index is calculated as follows:

Where:

$$
C A I=\frac{N i j / N i o}{N o j / N o o} X 100
$$

Nij denotes the number of papers co-authored by $\mathrm{j}$ authors in the i-th country,

Nio denotes the total number of papers in the i-th country, Noj denotes the number of papers co-authored by $\mathrm{j}$ authors in all countries,

Noo denotes the total number of papers in all countries.

$\mathrm{CAI}=100$ indicates that the number of publications corresponds to the average within a co-authorship pattern.
$\mathrm{CAI}>100$ reflects higher than the average, and $\mathrm{CAI}<100$ indicates lower than the average" (as cited in Guan \& Ma, 2007, p.114).

Table IV provides the co-authorship pattern of BRICS countries and these values depicted in the following figure 2. It is clear from the table that, in all the BRICS countries, the CAI value for India and China was more than 100 (average) in all authorship categories which shows that they preferred to work in small and big teams. In single-authored publications, Russia and South Africa, the CAI value stands more than the average value which indicates that these countries preferring to work independently. In two-authored publications of India and China, CAI value is exactly equal to the average CAI value which indicates the number of publications corresponds to the average within a coauthorship pattern, and the CAI value of South Africa is higher than the average, which represents this country prefer to work as a team. 
TABLE Iv CO-AuthorshiP PATTERn OF THE BRICS COUNTRIES

\begin{tabular}{|l|c|c|c|c|c|c|c|c|c|}
\hline Country & Single Author & CAI & Two Authors & CAI & Three Authors & CAI & >3 Authors & CAI & No. of Records \\
\hline Brazil & 378 & 79 & 469 & 95 & 364 & 90 & 771 & 127 & 1982 \\
\hline India & 420 & 90 & 480 & 101 & 407 & 104 & 615 & 105 & 1922 \\
\hline China & 732 & 68 & 1098 & 100 & 1097 & 122 & 1497 & 111 & 4424 \\
\hline Russia & 632 & 224 & 260 & 90 & 132 & 56 & 140 & 39 & 1164 \\
\hline S Africa & 483 & 142 & 394 & 113 & 218 & 76 & 311 & 72 & 1406 \\
\hline & 2645 & & 2701 & & 2218 & & 3334 & & 10898 \\
\hline
\end{tabular}

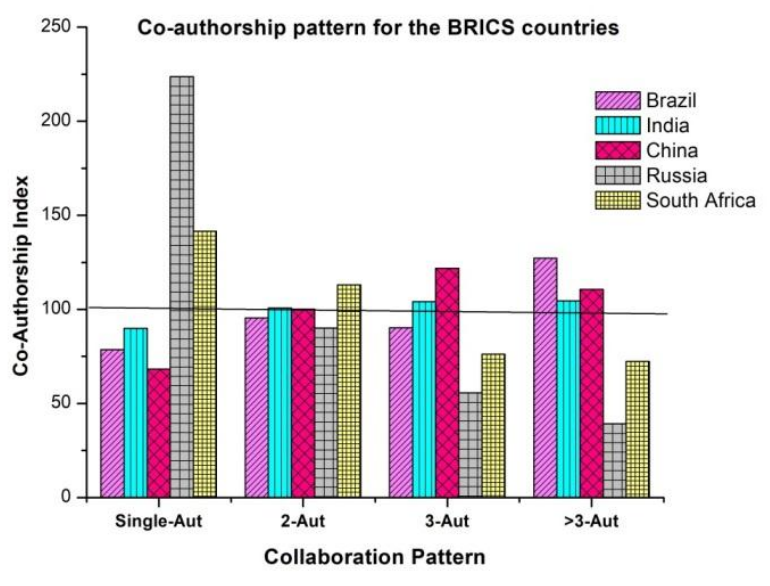

Fig. 2 Collaboration patterns reflected by CAI

\section{Transformative Activity Index (TAI)}

In order to study the change in the research output of the economics field of the BRICS counties, an index, Transformative Activity Index suggest by Guan \& Ma (2007) has applied with the following formula.

$$
T A I=\frac{C i / C o}{W t / W o} x 100
$$

$C i=$ Number of publications of the specific country in the $i^{\text {th }}$ block;

$C o=$ Total number of publications of the specific country during the period of study

$W i=$ Number of publications all the countries in the $\mathrm{i}^{\text {th }}$ block;

$W o=$ Total number of publications of all the countries during the period of study

Table V shows the publication output of economics research of the BRICS countries during the two blocks i.e. 19912003 and 2004-2016. By using the dataset, TAI for the two blocks has been calculated.

It is clear from the table that, the publication activity in economics research is increased exceptionally in all the BRICS countries. Chaitra, Jeyshankar, \& Abu (2014) found similar results in their study on Lung Cancer research in G7 and BRIC countries. China's publication activity (819) increased tremendously along with other BRICS countries such as Russia (764), Brazil (760), South Africa (720) and India (562) lag behind in terms of TAI.

TABle V Tai Of The Brics Countries

\begin{tabular}{|l|c|c|c|c|c|c|}
\hline Country & $\begin{array}{c}\text { 1991- } \\
\mathbf{2 0 0 3}\end{array}$ & TAI & $\begin{array}{c}\mathbf{2 0 0 4 -} \\
\mathbf{2 0 1 6}\end{array}$ & TAI & $\begin{array}{c}\mathbf{1 9 9 1 -} \\
\mathbf{2 0 1 6}\end{array}$ & $\begin{array}{c}\text { Change } \\
\text { in TAI }\end{array}$ \\
\hline Brazil & 194 & 92 & 1793 & 852 & 1987 & 760 \\
\hline China & 294 & 63 & 4133 & 881 & 4427 & 819 \\
\hline Inida & 389 & 191 & 1535 & 753 & 1924 & 562 \\
\hline Russia & 111 & 90 & 1051 & 854 & 1162 & 764 \\
\hline $\begin{array}{l}\text { South } \\
\text { Africa }\end{array}$ & 169 & 112 & 1255 & 832 & 1424 & 720 \\
\hline & 1157 & & 9767 & & 10924 & \\
\hline
\end{tabular}

Kumar \& Asheulova (2011) in their study highlighted that "... BRIC countries are projected to be the fastest growing economies in the world. The BRIC governments have declared education and $\mathrm{S} \& \mathrm{~T}$ to be a strategic engine of sustainable economic development. Therefore, BRIC governments are boosting their $\mathrm{R} \& \mathrm{D}$ investments and China, followed by India, has become an important player in research output. China was the third largest R\&Dperforming country in 2003, behind the United States and Japan and has increased the percentage of its GDP spent on R\&D. Among the BRIC countries, the gross domestic expenditure on R\&D as a percentage of GDP was highest in China (1.5\%), followed by Russian Federation (1.1\%), Brazil (1.0\%) and India (0.8\%) in 2007" (p.228). It can be inferred that, in order to improve the publication activity in India, more funding on the R\&D activities in general and in economics field of research, in particular, has to happen. It is also suggested that, most of the publications published in national languages, not digitized publication contents (inaccessible on Google Scholar and other search engines) and publications appeared in journals which are not indexed by well-known databases such as Web of Science, Scopus, etc. are difficult to find or to even to know of their existence, even though these publications represented highquality research. Policies can be made at the national or institutional level that all the publications published by respective organizations should be made open access so that electronic copies of the papers made available through open access repositories. This effort will enhance the visibility of research publications mentioned above and hence followed by the accessibility and impact. 


\section{Citation Profile of Economics Research for the BRICS Countries}

Citation profile of the BRICS countries is tabulated in the following Table VI. It is clear from the table that, in all the BRICS countries, out of 10929 publications, 2920 (26.7\%) publications did not receive any citations; remaining 8009 (73.3\%) publications received citations during the period of study from 1991-2016. A maximum of 2542 (23.3\%) papers cited from the range of 11-100 citations. An average citation per paper for all BRICS countries is 13.05. Only South Africa and China received citations more than the average citation rate. The h-index for papers of all BRICS countries is 122 .

It is interesting to note that, a considerable number 703 (60.3\%) of Russian papers did not receive any citations. On the other hand, an exceptionally high number of Chinese papers 3694 (83.4\%) got citations. South Africa papers cite with the highest average citation per paper rate of 16.09 percentile and Russian papers cited at the less average citation rate i.e. 7.4 percentile. Among the BRICS countries, China tops with a highest $\mathrm{h}$-index value of 92 , followed by India (64), South Africa (62), Brazil (60) and Russia (30) lagging far behind in the rank.

TABle Vi CitATION Profile OF THE BRICS COUNTRIES

\begin{tabular}{|c|c|c|c|c|c|c|}
\hline Citations Range & Brazil & China & India & Russia & S Africa & Total \\
\hline 0 & 654 & 733 & 504 & 703 & 326 & 2920 \\
\hline 1 & 215 & 498 & 264 & 153 & 178 & 1308 \\
\hline 2 & 164 & 399 & 169 & 70 & 108 & 910 \\
\hline 3 & 125 & 310 & 128 & 26 & 82 & 671 \\
\hline 4 & 94 & 244 & 99 & 37 & 60 & 534 \\
\hline 5 & 86 & 201 & 75 & 19 & 55 & 436 \\
\hline $06-10$ & 241 & 643 & 248 & 67 & 217 & 1416 \\
\hline $11-100$ & 379 & 1318 & 399 & 80 & 366 & 2232 \\
\hline $101-1000$ & 29 & 78 & 38 & 6 & 31 & 182 \\
\hline$>1000$ & 0 & 3 & 0 & 6 & 1 & 10 \\
\hline Total & 1987 & 4427 & 1924 & 1167 & 1424 & 10929 \\
\hline Total Citations & 23247 & 65559 & 22234 & 8630 & 22909 & 142579 \\
\hline Average Citation & 11.70 & 14.81 & 11.56 & 7.40 & 16.09 & 13.05 \\
\hline h-index & 60 & 92 & 64 & 30 & 62 & 122 \\
\hline
\end{tabular}

E. Absolute Citation Impact and Relative Citation Impact $(R C I)$

The Absolute Citation Impact (ACI) which is similar to the average citation per paper (CPP) and comparatively better indicator for measuring the performance of the research rather than considering either only total number of publications or the total number of citations. On the other hand, Relative Citation Impact (RCI) indicator was used to analyse the impact of BRICS countries. This indicator was developed by Thomson Reuters to calculate science and engineering indicators. (LalithaKumari, 2009), (Chitra, Jeyshankar, \& Abu, 2014).

$$
R C I=\frac{A \text { country's share of total citations }}{A \text { country'sshare of total publications }}
$$

$R C I=1$ indicates denotes a country's citation rate equal to world citation rate.

$R C I<I$ indicates a country's citation rate less than world citation rate and also implies that the research efforts are higher than its impact.

$R C I>1$ indicates a country's citation rate higher than world citation rate and also imply high impact research in that country.

TABLE VII ACI AND RCI OF BRICS COUNTRIES

\begin{tabular}{|l|c|c|c|c|c|c|}
\hline \multicolumn{1}{|c|}{ Country } & Publications & $\begin{array}{c}\text { BRICS share } \\
(\%) \text { publications }\end{array}$ & Citations & $\begin{array}{c}\text { BRICS share } \\
(\%) \text { Citations }\end{array}$ & ACI & RCI \\
\hline Brazil & 1987 & 18.19 & 23247 & 16.30 & 11.70 & 0.90 \\
\hline China & 4427 & 40.53 & 65559 & 45.98 & 14.81 & 1.13 \\
\hline Inida & 1924 & 17.61 & 22234 & 15.59 & 11.56 & 0.89 \\
\hline Russia & 1162 & 10.64 & 8630 & 6.05 & 7.43 & 0.57 \\
\hline South Africa & 1424 & 13.04 & 22909 & 16.07 & 16.09 & 1.23 \\
\hline & 10924 & & 142579 & & 13.05 & \\
\hline
\end{tabular}


The ACI and RCI values of BRICS countries shown in table VII. South Africa has the maximum ration of average citation per paper (CPP) 16.09, which signify the quality of research undertaken in the country, followed by China with 14.81 ACI, Brazil with 11.7 and India had somewhat closer citation values with Brazil and hence ACI value 11.56 is also more closer to it. Russia being the lowest ACI value with 7.43. For all the BRICS countries, South Africa and China, the RCI value is more than 1.00, i.e. 1.23 and 1.13 respectively indicating the higher citation impact. Brazil and India have almost equal RCI value 0.9 i.e. close to one indicate countries' citation rate is equal to that of BRICS share. Russia has RCI value less than one i.e. 0.57 indicate citation rate is less than other countries of study. Shashnov and Kotsemir (2018) got the similar results except for Russia in terms of citation metrics, they found that "For all BRICS countries except South Africa, the value of FWCI is below 1.00, i.e. less than the average global level of citation. South Africa, China, and Russia demonstrate quite rapid growth of the FWCI value" (p.1131).

\section{CONCLUSION}

Scientometric studies using the various bibliometric and economic indicators and techniques highlights the research contribution, performance and evaluation of various countries, institutions. The empirical data shows that BRICS countries contribution in social science subjects like economics is appreciable. China showed tremendous growth in research publication activities in economics after 2000 and other BRICS countries show steady growth. The collaboration effort in economics subject is comparatively less with science and technology arena. BRICS countries have tremendous potential in R\&D in social sciences.

\section{ACKNOWLEDGEMENT}

The author conveys sincere thanks to Indian Council of Social Science Research (ICSSR), New Delhi for providing financial support through Project titled "Scientometric Analysis of Research Output in the field of Economics among BRICS countries: A Study".

\section{REFERENCES}

[1] Amid BRICS' rise and 'Arab Spring', a new global order forms. (2011, 18 October). Christian Science Monitor.

[2] Balasubramani, R. Siriwardena, Asoka \& Abu, K. (2015). Science Funding Research Output in BRIC Countries: A
Scientometric Analysis. 10th International CALIBER-2015 HP University and IIAS, Shimla, Himachal Pradesh, India March 12-14, 2015 C INFLIBNET Centre, Gandhinagar, Gujarat, India.

[3] Bartosova, J., \& Bina, V. (2010). Influence of the relative poverty on the structure of household expenditures in the Czech Republic. In ICABR 2008-VI. International conference on applied business research Ras Al Khaimah 29.11. 2010-03.12, 19-28.

[4] Biradar, Nirmala \& Tadasad, P. G. (2015). Authorship patterns and collaborative research in economics. Journal of Indian Library Association, 51(4), pp. 21-29.

[5] Chitra, V., Jeyshankar, R., \& Abu, K. (2014). Lung Cancer Research in G7 and BRIC Countries: A Comparative Analysis by Scientometric Method. International Journal of Advanced Library and Information Science, 2(1), 72-81.

[6] Elango, B., Rajendran, P., \& J, M. (2013). Tribology Research Output in BRIC Countries: A Scientometric Dimension. Library Philosophy and Practice (e-journal), 935.

[7] Guan, J. C., Ma, N. (2007). A bibliometric study of Chin's semiconductor literature compared with other major Asian countries. Scientometrics, 70(1), 107-124.

[8] Kumar, N. and Asheulova, N. (2011, September). Comparative analysis of scientific output of BRIC countries. Annals of Library and Information Studies, 58, 228-236

[9] Lalitha Kumar, G. (2009) Synthetic Organic Chemistry Research: Analysis by Scientometric Indicators. Scientometrics, 80(3), 559-570.

[10] Savanur, K. P. \& Srikanth, R. (2010). Modified collaborative coefficient: a new measure for quantifying the degree of research collaboration, Scientometrics, 84, 365-371.

[11] Savanur, K. P. and Bakanatti, S. (2018). Scientometric Study of Mathematics research among BRICS Countries as reflected in Web of Science database during 2011-2015. Journal of Library Development (JLD), 4(2), p.25-29.

[12] Schubert, A., Braun, T. (1986). Relative indicators and relational charts for comparative assessment of publication output and citation impact. Scientometrics, 9, 281-291.

[13] Shashnov, S. \& Kotsemir, M. (2018). Research landscape of the BRICS countries, Scientometrics, 117, 1115-1155.

[14] World Economic Outlook (2013). IMF. April 2013.

[15] Wikipedia, accessed Dec. 2018, Retrieved from https://en.wikipedia.org/wiki/BRICS\#cite_note-IMFApr20138)

[16] Yang, L. Y., Yue, T., Ding, J. L., \& Han, T. (2012). A comparison of disciplinary structure in science between the G7 and the BRIC countries by bibliometric methods. Scientometrics, 93(2), 497-516.

[17] Yi, Y., Qi, W., \& Wu, D. (2013). Are CIVETS the next BRICs? A comparative analysis from scientometrics perspective. Scientometrics, 94(2), 615-628. 